\title{
PERENCANAAN PROSES PRODUKSI KEMASAN SIRUP WORTEL MENGGUNAKAN METODE QUALITY FUNCTION DEPLOYMENT
}

\author{
Yurida Ekawati dan Filemon Widjaja \\ Program Studi Teknik Industri Universitas Ma Chung Malang \\ Villa Puncak Tidar N1 Malang \\ e-mail: yurida.ekawati@machung.ac.id
}

\begin{abstract}
ABSTRAK
Perancangan kemasan produk makanan merupakan faktor yang penting dalam perancangan produk makanan. Kemasan bisa mempengaruhi kualitas produk makanan dan pemasarannya. Berdasarkan perencanaan desain kemasan produk sirup wortel yang telah dilakukan menggunakan metode Quality Function Deployment (QFD) tahap II, perencanaan proses produksi kemasan sirup wortel dilakukan menggunakan metode QFD tahap III atau proses planning. Langkah-langkah yang perlu dilakukan pada tahapan ini adalah menentukan proses utama dalam kegiatan produksi produk terkait, penentuan subproses (top-down process), dan proses identifikasi yang dilakukan bersamaan dengan proses eksperimen untuk mendapatkan critical process plan yang menjadi key operations pada proses produksi yang direncanakan. Hasil dari perencanaan proses produksi ini adalah matriks Process Planning untuk proses produksi kemasan sirup wortel. Pada matriks Process Planning yang telah terbentuk dapat diketahui bagian dari proses yang dianggap kritis atau critical process plan. Critical process plan pada proses produksi kemasan sirup wortel terdiri atas persiapan bahan baku kaca, pencampuran bahan baku kaca, proses melting dan refining, proses penstabilan suhu, proses forming, proses annealing dan pemberian label. Critical process plan yang memiliki prioritas tertinggi pada proses produksi kemasan sirup wortel adalah pemberian label dan proses forming. Selain matriks process planning dihasilkan pula operation process chart (OPC) untuk proses produksi kemasan sirup wortel.
\end{abstract}

Kata kunci: QFD, kemasan, perencanaan proses, sirup wortel

\begin{abstract}
The design of food product packaging is an important factor in the design of food products. Packaging can affect the quality of food products and their marketing. Based on the design planning of carrot syrup product that has been done using the method of Quality Function Deployment (QFD) phase II, the production process planning of carrot syrup packaging is done using QFD phase III method or planning process. The steps that need to be done at this phase are determining the main process in the production activities, the determination of the sub-process (top-down process), and the identification process that is carried out simultaneously with the experimental process to obtain the critical process plan which becomes the key operations in the planned production process. The result of this production process planning is Process Planning matrix for the production process of carrot syrup packaging. In the Process Planning matrix can be identified part of the process that is considered critical or critical process plan. Critical process plan in the production process of carrot syrup packaging consists of glass raw material preparation, glass raw material mixing, melting and refining process, temperature stability process, forming process, annealing process and labeling. Critical process plan that has the highest priority in the production process of carrot syrup packaging is labeling and forming process. In addition to the process planning matrix there is also an operation process chart (OPC) for the production process of carrot syrup packaging.
\end{abstract}

Keywords: QFD, packaging, process planning, carrot syrup

\section{PENDAHULUAN}

Wortel sangat sering digunakan sebagai bahan makanan atau masakan dikarenakan kandungan gizinya yang baik. Selain itu, wortel juga dikenal sebagai salah satu bahan pangan yang kaya akan kandungan mineral dan vitamin terutama vitamin A [1]. Selain itu wortel juga mengandung serat, gula dan antioksidan seperti vitamin C dan E [2]. Dalam upaya diversifikasi produk wortel, dapat dilakukan proses perancangan dan pengembangan produk olahan wortel. Metode yang digunakan untuk mendukung perancangan dan pengembangan produk olahan wortel tersebut adalah metode QFD (Quality Function Deployment). QFD merupakan metode yang digunakan untuk 
menerjemahkan suara konsumen pada proses perancangan dan pengembangan produk, sehingga didapati produk yang dapat memenuhi kebutuhan konsumen [3]. QFD terdiri dari beberapa tahapan utama, yaitu perencanaan produk, perencanaan komponen/desain, perencanaan proses produksi, dan pengendalian proses produksi [4]. Menurut Mukherjee [5], terdapat beberapa manfaat yang dapat dirasakan melalui penerapan QFD dalam proses perancangan dan pengembangan suatu produk yaitu produk ataupun jasa yang dihasilkan akan sesuai dengan voice of customer, biaya yang digunakan untuk proses perancangan produk, manufaktur produk, serta pelayanan akan menjadi lebih optimal (efektif dan efisien), dan berkurangnya waktu siklus yang dibutuhkan dalam proses pengembangan produk.

Perancangan suatu produk makanan tidak bisa dipisahkan dari perancangan kemasan produk makanan tersebut. Kemasan memberikan nilai pembeda pada suatu produk [6]. Hasil penelitian yang dilakukan oleh Ahmed dkk. [7] menunjukkan bahwa kemasan adalah salah satu faktor yang sangat penting dan kuat pengaruhnya pada keputusan membeli konsumen. Unsur-unsur dari kemasan yang mempengaruhi keputusan membeli konsumen adalah warna, material dan desain kemasan. Kemasan juga berperan sebagai alat pembeda dan membantu konsumen untuk memutuskan dalam memilih salah satu produk dari produkproduk yang sejenis [8].

Telah dilakukan penelitian terhadap produk olahan wortel yang berupa manisan wortel dan sirup wortel menggunakan metode Quality Function Deployment (QFD) tahap I [9]. Penelitian tersebut telah menghasilkan atribut-atribut yang dibutuhkan produk olahan wortel tersebut beserta kemasannya. Berdasarkan hasil QFD tahap I tersebut desain produk olahan wortel beserta kemasannya dikembangkan menggunakan QFD tahap II [10]. Berdasarkan desain produk tersebut maka perlu dilakukan langkah desain proses menggunakan QFD tahap III. Tahap ketiga pada metode QFD merupakan tahap perencanaan proses. Langkah pertama yang perlu dilakukan pada tahapan ini adalah menentukan proses utama dalam kegiatan produksi produk terkait.
Setelah menentukan proses utama pada kegiatan produksi, maka dilakukan penentuan sub-proses (top-down process). Setelah detail proses didapatkan, maka dengan menggunakan pengetahuan ahli akan dilakukan proses identifikasi bersamaan dengan proses eksperimen untuk mendapatkan critical process plan yang menjadi key operations pada proses produksi yang dilakukan [4].

Artikel ini akan membahas hasil penelitian terhadap perencanaan proses produksi kemasan produk sirup wortel menggunakan QFD tahap III berdasarkan hasil dari matriks desain produk yang dihasilkan untuk kemasan produk sirup wortel menggunakan QFD tahap II.

\section{METODE PENELITIAN}

Pada proses pengolahan data dengan menggunakan metode QFD tahap ketiga, terdapat beberapa tahapan yang harus dilakukan. Berikut merupakan tahapan-tahapan yang harus dilakukan pada proses pengolahan data tersebut:

1. Menentukan Critical Parts Terpilih

Langkah awal yang perlu dilakukan pada penggunaan metode QFD tahap ketiga adalah menentukan critical parts terpilih yang diperoleh dari hasil pembuatan matriks QFD tahap kedua. Pada QFD tahap ketiga akan dilakukan proses pencarian relasi antara critical parts terpilih dengan rencana proses yang telah ditentukan.

2. Menentukan Rencana Proses

Pada tahapan ini, dilakukan analisis terhadap alur proses kritis pada proses produksi produk yang dihasilkan. Penentuan rencana proses dapat dilakukan dengan melakukan kegiatan wawancara serta diskusi dengan praktisi yang ahli dalam proses produksi sirup dan praktisi yang ahli dalam proses produksi kemasan sirup (botol sirup).

3. Menentukan Nilai Kepentingan

Pada tahapan ini, ditentukan nilai kepentingan untuk masing-masing critical parts. Critical parts yang memiliki prioritas yang tinggi akan memiliki nilai kepentingan yang tinggi pula. Nilai kepentingan dapat 
dihitung dengan menggunakan rumus sebagai berikut:

Nilai Kepentingan $=\frac{\text { Bobot Kepentingan Critical Parts }}{\text { Total Bobot Kepentingan Desain }}$

Selain mencari nilai kepentingan, juga perlu dicari nilai bobot relatif critical parts terpilih yang berfungsi sebagai salah satu komponen dalam perhitungan bobot kepentingan critical process plan. Berikut merupakan rumus untuk menghitung bobot relatif critical parts terpilih:

Bobot Relatif Critical Parts Terpilih $=$

$\frac{\text { Bobot Kepentingan Critical Parts }}{\text { Total Bobot Kepentingan Critical Parts }} \times 100 \%$

4. Membuat Matriks Korelasi antara Critical Parts dengan Critical Process Plan

Pada tahapan ini dilakukan proses penentuan nilai korelasi antara critical parts dengan critical process plan yang sudah ditentukan. Penentuan korelasi tersebut dilakukan dengan cara memberikan nilai yang sesuai pada kolom irisan critical parts dengan critical process plan yang diinginkan. Masing-masing critical parts dapat memengaruhi lebih dari satu critical process plan dan berlaku pula sebaliknya. Dalam melakukan penilaian tersebut, terdapat nilai ataupun simbol khusus yang digunakan. Berikut merupakan nilai beserta dengan simbol yang digunakan dalam proses penilaian korelasi pada matriks korelasi (Tabel 1).

Tabel 1. Format Penilaian Matriks Korelasi

\begin{tabular}{ccc}
\hline Nilai & Simbol & Keterangan \\
\hline 0 & (kosong) & Tidak ada hubungan \\
1 & $\Delta$ & Hubungan lemah \\
3 & $\circ$ & Hubungan sedang \\
9 & $\bullet$ & Hubungan kuat \\
\hline
\end{tabular}

5. Menentukan Bobot Kepentingan

Perhitungan bobot kepentingan dilakukan dengan cara mengalikan nilai bobot relatif critical parts dengan nilai hubungan antara critical parts dengan critical process plan. Berikut merupakan rumus untuk menghitung bobot kepentingan critical process plan:

\section{Bobot Kepentingan Critical Process Plan $=$ (Bobot Relatif Critical Parts $\times$ $\sum$ Nilai Hubungan Critical Parts dengan Critical Process Plan)}

6. Menyusun Matriks Process Planning Setelah melakukan berbagai perhitungan dan pengolahan data terkait process planning, langkah terakhir dalam kegiatan pengolahan data yang perlu dilakukan adalah meletakkan hasil perhitungan beserta dengan hasil pengolahan data yang telah dilakukan pada matriks process planning.

\section{HASIL DAN PEMBAHASAN}

Tahap ketiga pada metode QFD merupakan tahap perencanaan proses yang bertujuan untuk mendapatkan critical process plan terkait proses produksi suatu produk tertentu. Critical process plan dapat ditentukan dengan cara membuat matriks process planning. Pada proses penyusunan matriks process planning terdapat beberapa langkah atau tahapan yang harus dilakukan, diantaranya adalah menentukan critical parts terpilih, menentukan rencana proses, menentukan nilai kepentingan, membuat matriks korelasi antara critical parts dan critical process plan serta menentukan bobot kepentingan critical process plan.

\section{Menentukan Critical Parts Terpilih Kemasan Produk Sirup Wortel}

Langkah awal yang perlu dilakukan dalam menggunakan metode QFD tahap ketiga adalah menentukan critical parts terpilih yang diperoleh dari hasil pembuatan matriks QFD tahap kedua untuk kemasan produk sirup wortel. Berdasarkan penelitian terdahulu dengan menggunakan metode QFD tahap kedua, didapati beberapa critical parts untuk kemasan produk sirup wortel beserta dengan bobot kepentingannya sebagai berikut (Ekawati dan Bazarado, 2016): 
Tabel 2. Critical Parts untuk Kemasan Produk Sirup Wortel

\begin{tabular}{|c|c|c|}
\hline Critical Parts & $\begin{array}{c}\text { Bobot } \\
\text { Kepentingan }\end{array}$ & Prioritas \\
\hline Pencantuman Label & 634,6479 & 1 \\
\hline Tipe Desain Kemasan & 342,023 & 2 \\
\hline Cara Pengemasan & 304,6863 & 3 \\
\hline Desain Iklan & 163,5595 & 4 \\
\hline Jenis Bahan Kemasan & 112,0102 & 5 \\
\hline
\end{tabular}

\section{Menentukan Rencana Proses Produksi Kemasan Produk Sirup Wortel}

Pada tahapan ini, dilakukan penentuan alur proses kritis pada proses produksi kemasan produk sirup wortel. Kemasan produk sirup wortel yang digunakan adalah kemasan berupa botol kaca. Penentuan rencana proses produksi kemasan produk sirup tersebut dapat dilakukan melalui kegiatan wawancara serta diskusi dengan praktisi yang ahli dalam proses produksi botol kaca. Secara garis besar rencana proses dapat dibagi menjadi dua bagian, yaitu rencana proses primer dan rencana proses sekunder. Rencana proses primer merupakan rencana proses yang cenderung bersifat lebih umum, sedangkan rencana proses sekunder merupakan rencana proses yang bersifat lebih spesifik serta merupakan turunan (derivat) dari rencana proses primer. Gambar 1 merupakan bagan rencana proses primer dan sekunder untuk proses produksi kemasan produk sirup wortel.

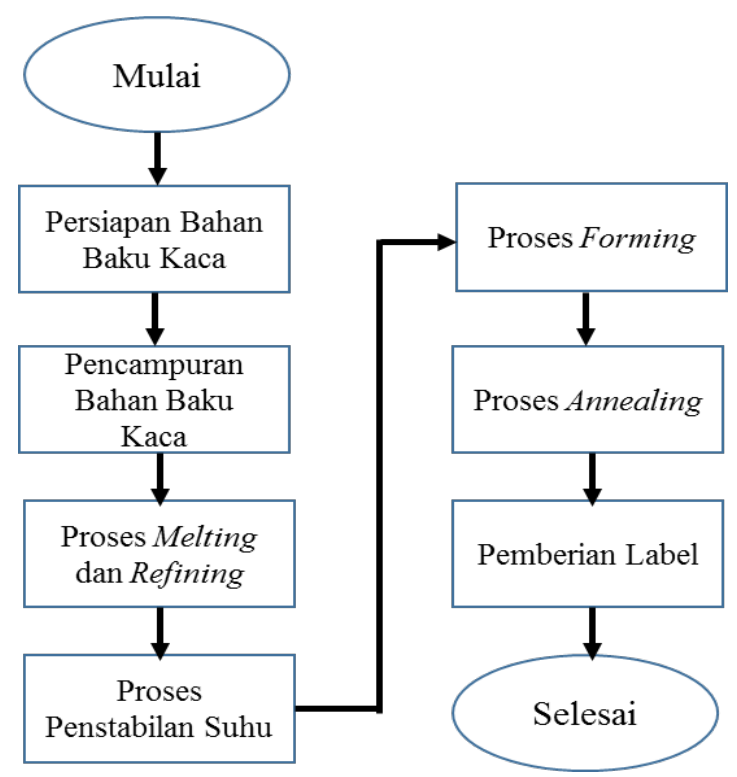

Gambar 1. Diagram Alir Proses Produksi Kemasan Produk Sirup Wortel
Proses produksi botol kaca diawali dengan persiapan bahan baku kaca, diantaranya adalah kalsium karbonat, sodium karbonat, pasir silika dan bahan-bahan lainnya. Setelah bahan baku siap, maka akan dilakukan proses pencampuran bahan baku. Setelah selesai dilakukan proses pencampuran, campuran bahan baku akan dikirim ke tungku (furnace) hopper untuk melalui proses melting dan refining. Campuran bahan baku akan dibakar di dalam tungku dan melalui proses melting serta refining dimana suhu pembakaran di dalam tungku berkisar antara $1450^{\circ}$ Celcius hingga $1575^{\circ}$ Celcius. Proses melting bertujuan untuk melebur bahan baku serta melepas gelembunggelembung yang besar sehingga cairan kaca hanya mengandung gelembung kecil saja, sedangkan proses refining bertujuan untuk melepas gelembung-gelembung kecil yang ada pada cairan kaca. Hasil leburan pada proses melting dan refining disebut sebagai gob. Setelah melalui proses melting dan refining, gob yang dihasilkan akan mengalami proses penstabilan suhu dikarenakan suhu gob masih terlampau tinggi usai proses pembakaran di tungku.

Tabel 3. Rencana Proses Primer dan Sekunder pada Proses Produksi Kemasan Produk Sirup Wortel

\begin{tabular}{|c|c|}
\hline $\begin{array}{c}\text { Rencana } \\
\text { Proses } \\
\text { Primer } \\
\end{array}$ & $\begin{array}{l}\text { Rencana Proses } \\
\text { Sekunder }\end{array}$ \\
\hline $\begin{array}{l}\text { Persiapan } \\
\text { bahan baku }\end{array}$ & $\begin{array}{l}\text { Persiapan bahan baku kaca } \\
\text { Pencampuran bahan baku kaca }\end{array}$ \\
\hline $\begin{array}{l}\text { Proses } \\
\text { produksi }\end{array}$ & $\begin{array}{l}\text { Proses melting dan refining } \\
\text { Proses penstabilan suhu } \\
\text { Proses forming } \\
\text { Proses annealing }\end{array}$ \\
\hline Pelabelan & Pemberian label \\
\hline
\end{tabular}

Setelah suhu gob stabil, maka gob akan melalui proses forming yang mengubah bentuk gob menjadi bentuk yang diinginkan. Pada proses forming, pertama-tama gob akan memasuki blank-mould untuk membentuk neck ring \& parison (botol setengah jadi). Selanjutnya botol setengah jadi tersebut akan memasuki blow-mould dimana botol setengah jadi yang ada akan ditiup dengan angin 
bertekanan tinggi sehingga bentuk botol setengah jadi akan mengikuti bentuk cetakan (mould) yang ada. Melalui proses forming pada blow-mould, akan didapatkan bentuk botol yang sesuai dengan keinginan.

Sesudah melalui proses forming, botol kaca yang telah jadi akan melalui proses annealing, yaitu proses penurunan temperatur atau suhu botol secara bertahap. Tujuan dari proses annealing tersebut adalah untuk meghilangkan tegangan dan regangan saat terjadinya proses pembentukan botol pada bagian forming sehingga membuat botol kaca menjadi lebih kuat. Proses terakhir adalah proses pemberian label pada botol kaca. Proses pemberian label dapat dilakukan dengan menggunakan cara manual ataupun dengan menggunakan mesin. Pemberian label secara manual dapat dilakukan dengan cara menempelkan label dengan perekat pada botol kaca, sedangkan pemberian label dengan mesin dapat dilakukan dengan menggunakan mesin printing khusus. Oleh karena produk kemasan sirup wortel yang akan diproduksi merupakan produk baru, maka keseluruhan rencana proses yang ada dapat dijadikan sebagai critical process plan.

\section{Menentukan Nilai Kepentingan Critical Parts Kemasan Produk Sirup Wortel}

Pada tahapan ini, ditentukan nilai kepentingan untuk masing-masing critical parts pada kemasan produk sirup wortel. Fungsi dari nilai kepentingan ini adalah untuk menggambarkan kepentingan masing-masing critical parts terpilih untuk menghasilkan produk yang sesuai dengan critical process plan yang diharapkan. Selain menentukan nilai kepentingan, juga perlu dilakukan proses penentuan bobot relatif critical parts terpilih yang akan digunakan dalam perhitungan pada tahap selanjutnya. Nilai bobot relatif critical parts terpilih dapat diperoleh dari perbandingan masing-masing bobot kepentingan desain terhadap total bobot kepentingan desain yang terpilih menjadi critical parts. Perhitungan nilai kepentingan dan bobot relatif critical parts terpilih dilakukan pada semua critical parts terpilih. Tabel 4 merupakan nilai kepentingan beserta dengan bobot relatif critical parts terpilih untuk kemasan produk sirup wortel.

\section{Membuat Matriks Korelasi antara Critical Parts dengan Critical Process Plan Kemasan Produk Sirup Wortel}

Pada tahapan ini dilakukan proses penentuan nilai korelasi atau hubungan antara critical parts dengan critical process plan yang sudah ditentukan. Penentuan korelasi tersebut dilakukan dengan cara memberikan nilai yang sesuai pada kolom irisan critical parts dengan critical process plan yang diinginkan. Masingmasing critical parts dapat memengaruhi lebih dari satu critical process plan dan dapat berlaku sebaliknya. Nilai yang digunakan pada penentuan nilai korelasi ini adalah 0 (tidak ada hubungan), 1 (hubungan lemah), 3 (hubungan sedang), dan 9 (hubungan kuat). Matriks korelasi antara critical parts dengan critical process plan pada proses produksi kemasan produk sirup wortel bisa dilihat di Gambar 2.

\section{Menentukan Bobot Kepentingan Critical Process Plan pada Proses Produksi Kemasan Produk Sirup Wortel}

Pada tahapan ini, dilakukan proses perhitungan bobot kepentingan masing-masing critical process plan dengan cara mengalikan nilai bobot relatif critical parts dengan nilai hubungan antara critical parts dengan critical

Tabel 4. Nilai Kepentingan dan Bobot Relatif Critical Parts Terpilih Kemasan Produk Sirup Wortel

\begin{tabular}{lrrr}
\hline \multicolumn{1}{c}{ Critical Parts } & $\begin{array}{c}\text { Nilai } \\
\text { Kepentingan }\end{array}$ & $\begin{array}{c}\text { Bobot Kepentingan } \\
\text { Desain }\end{array}$ & $\begin{array}{c}\text { Bobot Relatif Critical } \\
\text { Parts Terpilih (\%) }\end{array}$ \\
\hline Pencantuman Label & 0,408 & 634,6479 & 40,76 \\
Tipe Desain Kemasan & 0,220 & 342,023 & 21,97 \\
Cara Pengemasan & 0,196 & 304,6863 & 19,57 \\
Desain Iklan & 0,105 & 163,5595 & 10,51 \\
Jenis Bahan Kemasan & 0,072 & 112,0102 & 7,19 \\
\hline Total & & $\mathbf{1 5 5 6 , 9 2 7}$ & $\mathbf{1 0 0}$ \\
\hline
\end{tabular}


process plan. Perhitungan bobot kepentingan dilakukan untuk semua critical process plan pada proses produksi kemasan produk sirup wortel yang ada. Tabel 5 menunjukkan hasil perhitungan bobot kepentingan critical process plan pada proses produksi kemasan produk sirup wortel. Setelah mendapatkan bobot kepentingan untuk masing-masing critical process plan, dilakukanlah proses pengurutan prioritas critical process plan dari nilai bobot kepentingan yang terbesar. Tabel 6 merupakan hasil pengurutan critical process plan pada proses produksi kemasan produk sirup wortel dari bobot kepentingan terbesar (prioritas lebih tinggi). Berdasarkan perhitungan bobot kepentingan critical process plan, didapati beberapa critical process plan yang menjadi prioritas utama, yaitu pemberian label dan proses forming.

Tabel 5. Bobot Kepentingan Critical Process Plan pada Proses Produksi Kemasan Sirup Wortel

\begin{tabular}{|c|c|c|}
\hline \multicolumn{2}{|c|}{ Critical Process Plan } & $\begin{array}{c}\text { Bobot } \\
\text { Kepentingan }\end{array}$ \\
\hline Persiapan bahan bak & kaca & 64,75 \\
\hline Pencampuran bahan & aku kaca & 64,75 \\
\hline Proses melting dan $r$ & ining & 64,75 \\
\hline Proses penstabilan st & & 21,58 \\
\hline Proses forming & & 287,94 \\
\hline Proses annealing & & 64,75 \\
\hline Pemberian label & & 520,12 \\
\hline \multicolumn{3}{|c|}{$\begin{array}{l}\text { Tabel 6. Prioritas Critical Process Plan pada } \\
\text { Proses Produksi Kemasan Sirup } \\
\text { Wortel }\end{array}$} \\
\hline $\begin{array}{c}\text { Critical Process } \\
\text { Plan }\end{array}$ & $\begin{array}{c}\text { Bobot } \\
\text { Kepentingan }\end{array}$ & Prioritas \\
\hline Pemberian label & 520,12 & 1 \\
\hline Proses forming & 287,94 & 2 \\
\hline $\begin{array}{l}\text { Persiapan bahan } \\
\text { baku kaca }\end{array}$ & 64,75 & 3 \\
\hline $\begin{array}{l}\text { Pencampuran bahan } \\
\text { baku kaca }\end{array}$ & 64,75 & 3 \\
\hline $\begin{array}{l}\text { Proses melting dan } \\
\text { refining }\end{array}$ & 64,75 & 3 \\
\hline Proses annealing & 64,75 & 3 \\
\hline $\begin{array}{l}\text { Proses penstabilan } \\
\text { suhu }\end{array}$ & 21,58 & 4 \\
\hline
\end{tabular}

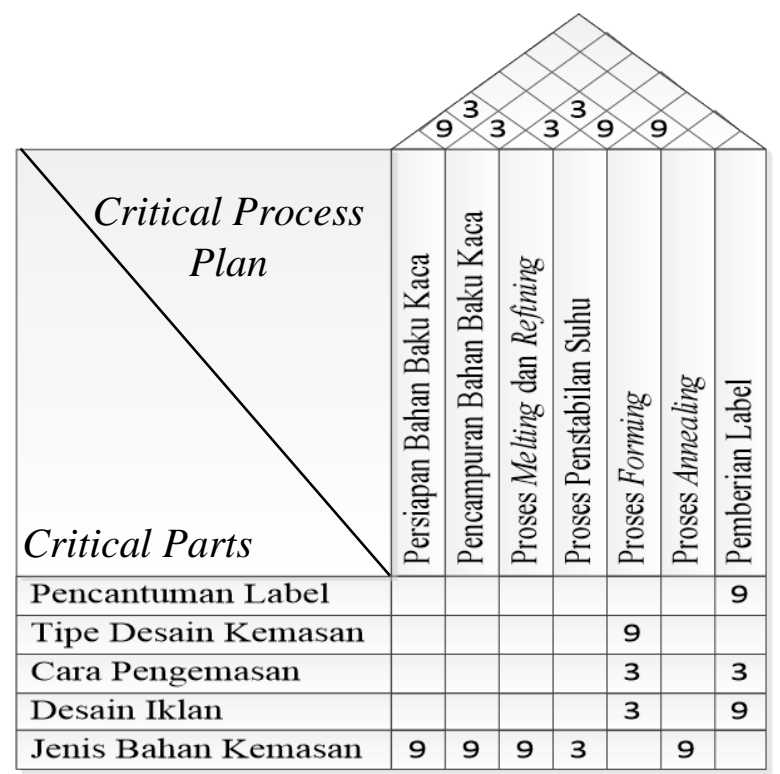

Gambar 2. Matriks Korelasi pada QFD Tahap Ketiga Kemasan Produk Sirup Wortel

\section{Matriks Process Planning pada Proses Produksi Kemasan Produk Sirup Wortel}

Setelah melakukan seluruh perhitungan dan pengolahan data terkait process planning, langkah terakhir dalam kegiatan pengolahan data yang perlu dilakukan adalah meletakkan hasil perhitungan beserta dengan hasil pengolahan data yang telah dilakukan pada matriks process planning. Gambar 3 merupakan matriks process planning pada proses produksi kemasan produk sirup wortel:

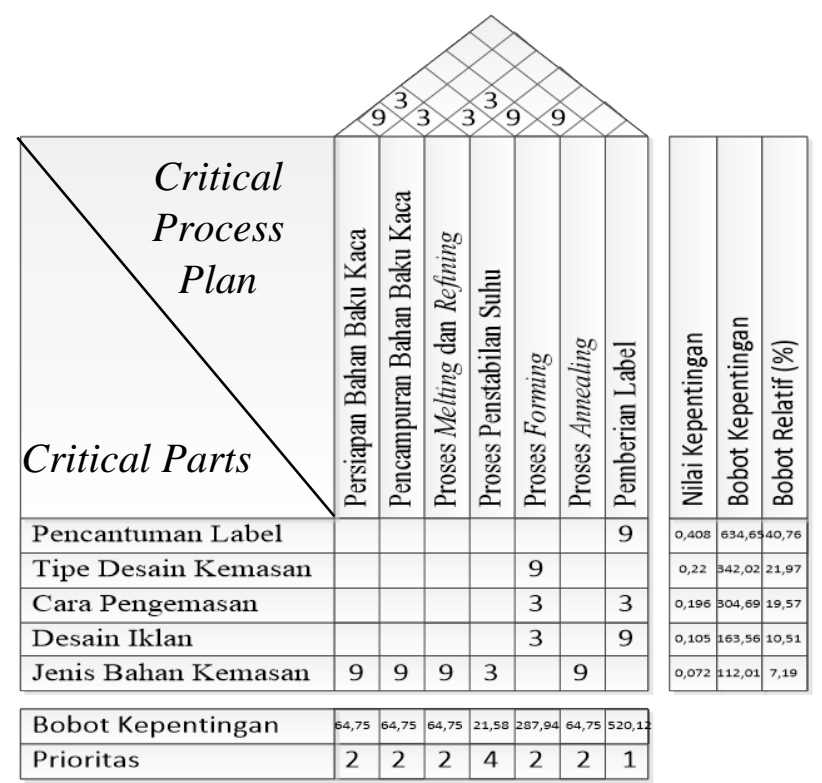

Gambar 3. Matriks Process Planning untuk Proses Produksi Kemasan Sirup Wortel 


\section{Operation Process Chart untuk Proses Produksi Kemasan Produk Sirup Wortel}

Berdasarkan hasil analisis dan pengolahan data yang telah dilakukan, urutan proses produksi kemasan produk sirup wortel dapat digambarkan dalam bentuk Operation Process Chart (OPC). OPC dari kemasan produk sirup wortel dapat dilihat pada Gambar 4.

\section{OPERATION PROCESS CHART Kemasan Produk Sirup Wortel}

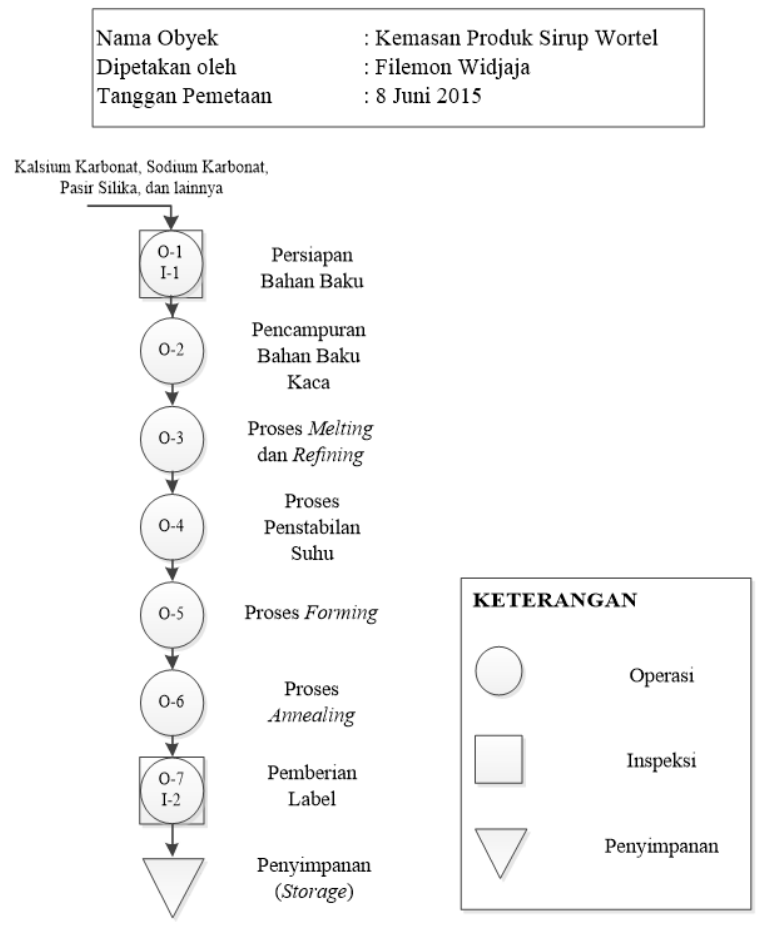

Gambar 4. Operation Process Chart Kemasan Sirup Wortel

\section{PEMBAHASAN}

Berdasarkan

perhitungan

serta pengolahan data yang telah dilakukan, didapati bahwa critical process plan untuk kemasan produk sirup wortel yang memiliki prioritas tertinggi adalah proses pemberian label dengan nilai bobot kepentingan sebesar 520,12. Tingginya nilai bobot kepentingan tersebut menunjukkan bahwa critical process plan tersebut memegang peranan yang penting dalam proses produksi kemasan sirup wortel. Pemberian label menjadi salah satu atribut yang penting dikarenakan label merupakan salah satu daya tarik konsumen untuk membeli suatu produk. Label dengan desain yang menarik serta informasi yang jelas akan membuat konsumen memiliki keinginan untuk membeli produk tersebut. Critical process plan selanjutnya yang menempati prioritas kedua adalah proses forming dengan nilai bobot kepentingan sebesar 287,94. Proses forming merupakan salah satu proses yang penting pada proses pembuatan botol kaca dikarenakan proses forming menentukan bentuk botol kaca yang ingin dibuat.

Critical process plan yang menempati urutan prioritas ketiga adalah proses persiapan bahan baku kaca, pencampuran bahan baku kaca, proses melting dan refining dan proses annealing. Proses persiapan bahan baku kaca dan pencampuran bahan baku kaca cukup krusial untuk diperhatikan karena proses-proses tersebut menentukan kandungan dari botol kaca yang diproduksi. Kandungan dari botol kaca tersebut nantinya akan menentukan karakterisitik dari botol kaca yang diproduksi. Proses melting dan refining serta annealing juga menentukan kualitas botol kaca yang diproduksi. Proses-proses tersebut membutuhkan suhu yang tepat untuk bisa mendapatkan kualitas botol kaca yang baik.

\section{KESIMPULAN}

Critical process plan pada proses produksi kemasan produk sirup wortel terdiri atas persiapan bahan baku kaca, pencampuran bahan baku kaca, proses melting dan refining, proses penstabilan suhu, proses forming, proses annealing dan pemberian label. Critical process plan yang memiliki prioritas tertinggi pada proses produksi kemasan produk sirup wortel adalah pemberian label dan proses forming. Penelitian ini dapat dilanjutkan dengan penelitian yang lebih lanjut diantaranya melalui penelitian dengan menggunakan metode desain eksperimen untuk mendapatkan parameterparameter optimal desain kemasan.

\section{DAFTAR PUSTAKA}

[1] Cahyono, B. (2002) Wortel, Teknik Budi Daya dan Analisis Usaha Tani. Yogyakarta: Kanisius.

[2] Alasalvar, C., Grigor, J.M.. Zhang, D. Quantic, P.C. dan Shahidi, F. (2001). Comparison of Volatiles, Phenolics, 
Sugar, Antioxidant Vitamins, and Sensory Quality of Different Colored Carrot Varietes. J Agric Food Chem. Vo. 49, pp. 1410-1416.

[3] Akao, Y. (2004). Quality Function Deployment: Integrating Customer Requirements Into Product Design. Boca Raton: Taylor and Francis.

[4] Cohen, L. (1995) Quality function deployment: how to make QFD work to you. Boston: Addison-Wesley Publishing Company.

[5] Mukherjee, P. N. (2006). Total quality management. New Delhi: PHI Learning Pvt. Lt

[6] Silayoi, P., dan Speece, M. (2007). The Importance of Packaging Attributes: A Conjoint Analysis Approach. European Journal of Marketing, 41 (11/12), pp. 1495-1517.

[7] Ahmed, Rizwan, R., Parmar, V. dan Amin, Muhammad. A. (2014). Impact of Product Packaging on Consumer's Buying Behavior. European Journal of Scientific Research 120 (2), pp. 145-157.
[8] Wells, L.E., Farley, H., dan Armstrong, G.A., 2007. The Importance of Packaging Design for Own-Label Food Brands. International Journal of Retail \& Distribution Management, 35 (9), pp. 677-690.

[9] Halim, V. and Ekawati, Y. (2014). Perencanaan Produk Olahan Wortel Menggunakan Metode Quality Function Deployment. Symbol, Vol. 1, no. 1, pp 57-67.

[10] Ekawati, Y. dan Bazarado, M. (2016). Designing Food Products Based on Carrots Using the Product Design Phase of Quality Function Deployment. ARPN Journal of Engineering and Applied Sciences, Vol. 11, no. 5, pp. 3109-3116. 